events in 2 (testicular abscess and worsening renal failure) and refractory disease in 2.

Conclusion: The results of this study suggest that TNF-alpha blockers and TCZ may achieve higher rates of remission and GC-sparing in relapsing and/or refractory PAN than other biologics. Our data warrant further study to confirm or not these findings.

Disclosure of Interests: : Alice Canzian: None declared, Omer Karadag: None declared, Anne Contis: None declared, Francois Maurier: None declared, Silvia Sartorelli: None declared, Laure Denis: None declared, Sebastien Sanges: None declared, Claire De Moreuil: None declared, Cécile-Audrey Durel: None declared, Stephane Durupt: None declared, Marie Jachiet: None declared, Diane Rouzaud: None declared, Carlo Salvarani: None declared, Franco Schiavon: None declared, Lorenzo Dagna Consultant for: Prof Lorenzo Dagna received consultation honoraria from Abbvie, Amgen, Biogen, Bristol-Myers Squibb, Celltrion, Novartis, Pfizer, Sanofi-Genzyme, and SOBI., Fabrice Bonnet: None declared, David Jayne Grant/research support from: David Jayne has received research grants from Chemocentryx, GSK, Roche/Genentech and Sanofi-Genzyme. He has received consultancy fees from Astra-Zeneca, Boehringer-Ingelheim, Chemocentryx, Chugai, GSK, Infla-RX, Insmed and Takeda, Loïc Guillevin: None declared, Benjamin Terrier: None declared DOI: 10.1136/annrheumdis-2019-eular.7185

\section{SAT0222 COOPERATION OF T FOLLICULAR HELPER CELLS AND B CELLS IN TERTIARY LYMPHOID STRUCTURES IN TAKAYASU ARTERITIS}

Anne-Claire Desbois ${ }^{1}$, Anna Maciejewski-Duval ${ }^{2}$, Paul Régnier ${ }^{2}$,

Valentin Quiniou ${ }^{2}$, Cloé Comarmond ${ }^{2}$, Hélène Vallet ${ }^{2}$, Patrick Bruneval ${ }^{3}$,

Pierre Fouret ${ }^{2}$, Michele Rosenzwajg ${ }^{2}$, David Klatzmann ${ }^{2}$, Fabien Koskas ${ }^{2}$ Marlène Garrido ${ }^{2}$, Guillaume Darrasse-Jèze ${ }^{2}$, Patrice Cacoub ${ }^{2}$, David Saadoun ${ }^{2}$.

${ }^{1}$ GHPS, Paris, France; ${ }^{2}$ Groupe Hospitalier La Pitié Salpétrière, Paris, France;

${ }^{3}$ HEGP, Paris, France

Background: Takayasu's arteritis (TA) and giant cell arteritis (GCA), the two most common types of large vessel vasculitis (LVV), are characterized by an arterial inflammatory granulomatous infiltrate mainly located in the media and the adventitia. However, distinct histological features of the immune response are poorly known.

Objectives: To investigate distinct pathological mechanisms of the immune response in patients with GCA and TA.

Methods: We performed comparative immunohistochemistry analysis of aorta of GCA and TA patients. We performed microarray gene analysis of purified CD4+ T cells of TA and GCA patients. Reverse transcriptase PCR, flow cytometry analysis and cell culture were used to investigate $T$ and B cells subpopulations in 54 patients with TA, 52 with GCA and 60 controls.

Results: We found higher proportion of tertiary lymphoid structures composed of CXCR5+, CD4+, PD-1+ and CD-20+ cells in inflammatory aortic lesions in TA as compared to GCA. We demonstrated increased proportion of aortic B cells in TA.

We next evaluated differentiation of circulating CD4+ T cells in both diseases. Among sixty-seven genes differentially expressed in CD4+ $T$ cells of TA compared to GCA patients, we identified a specific "T follicular helper" (Tfh) signature in TA patients. We also found a specific Tfh 17 signature in TA patients. Flow cytometry analysis confirmed increased circulating Tfh, defined as CXCR5+ CD4+ T cells, in TA patients as compared to GCA and healthy donors (HD) [median of $15.4 \quad(10 ; 30.8) \%$ versus $5.3(1.4 ; 12.2) \%$ and $9.7 \quad(5.6 ; 12.5) \% \quad(p<0.0001$ and $p=0.0001)]$ in TA, GCA and HD, respectively. Among Tfh subpopulations, Tfh-17, CXCR5+ CCR6+ CXCR3- CD4+, cells were specifically increased in TA.

Functionally, CXCR5+ CD4+ T cells of TA patients helped B cells to differentiate into memory cells, to proliferate and to secrete type $G$ immunoglobulins.

We sequenced the TCR repertoire $\alpha / \beta$ in CD3+CD4+CXCR5- and CD3 +CD4+CXCR5+ cells, in aortic and blood samples from 2 patients. In both patients, we identified oligoclonal profile of TCR repertoire only for aortic CXCR5+ cells, suggesting antigenic selection of CXCR5+ CD4+ T cells.

Conclusion: We provide evidence of the presence of tertiary lymphoid structures composed of Tfh and B cells in TA aorta. We identified a specific Tfh signature in circulating CD4+ $T$ cells that distinguishes TA and GCA patients. The key cooperation of Tfh and B cells in TA and the oligoclonal repertoire of CXCR5+ CD4+ T cells strongly suggest the role of antigenic trigger.

Disclosure of Interests: : Anne-Claire DESBOIS Speakers bureau: SOBI en 2015, Anna Maciejewski-Duval: None declared, Paul Régnier: None declared, Valentin QUINIOU: None declared, Cloé Comarmond: None declared, Hélène Vallet: None declared, Patrick Bruneval: None declared, Pierre Fouret: None declared, Michele Rosenzwajg: None declared, David Klatzmann: None declared, Fabien Koskas: None declared, Marlène Garrido: None declared, Guillaume Darrasse-Jèze: None declared, Patrice cacoub Consultant for: d'Abbvie, Astra Zeneca, Bayer, Boehringer Ingelheim, Gilead, Glaxo Smith Kline, Janssen, Merck Sharp Dohme, Pfizer, Roche, Servier, and Vifor., Speakers bureau: d'Abbvie, Astra Zeneca Bayer, Boehringer Ingelheim, Gilead, Glaxo Smith Kline, Janssen, Merck Sharp Dohme, Pfizer, Roche, Servier, and Vifor., David Saadoun Grant research support from: Roche, Abbvie, Consultant for: Janssen, Celgene, Abbvie, Roche DOI: 10.1136/annrheumdis-2019-eular.4852

\section{SAT0223 FACTORS ASSOCIATED WITH DAMAGE PROGRESSION IN BEHÇET'S SYNDROME UVEITIS}

Yilmaz Ozyazgan ${ }^{1}$, Didar Ucar ${ }^{1}$, Mustafa Erdogan ${ }^{2}$, Yesim Ozguler ${ }^{2}$,

Gulen Hatemi ${ }^{2}$, Sebahattin Yurdakul ${ }^{2}$, Vedat Hamuryudan ${ }^{2}$, Izzet Fresko ${ }^{2}$ Melike Melikoglu², Emire Seyahi ${ }^{2}$, Serdal Ugurlu ${ }^{2}$, Hasan Yazici ${ }^{2} .{ }^{1}$ Istanbu University -Cerrahpasa Medical Faculty, Department of Ophthalmology, Istanbul, Turkey, ${ }^{2}$ Istanbul University - Cerrahpasa, Cerrahpasa Medical Faculty, Internal Medicine, Division of Rheumatology, Istanbul, Turkey

Background: Uveitis in Behçet's syndrome (BS) follows a recurrent disease course with inflammatory exacerbations causing damage in the uvea, retina and optic nerve even with treatment. Frequent attacks and posterior involvement are considered as predictors of poor visual outcome.

Objectives: The aim of this study is to delineate the predictors of damage in more detail using a standard screening method among a group of BS patients with long term regular follow-up.

Methods: Patients with uveitis who were registered in our multidisciplinary BS clinic between 1990 and 2008 were screened. Among these, 50 patients who were followed for at least 10 years, who were regularly seen in our clinic at least once in every 4 months, who did not have > Grade 2 damage at baseline, and who represented different levels of damage severity during the last visit (between Grade 0 and 5) were selected. The damage severity was graded according to a validated dam age grading instrument (5=worst) specifically developed for BS uveitis (Ozyazgan et al. in preparation). One patient was later excluded because it was realized that he did not fulfill these criteria. A standard form was used for retrieving data on demographics, baseline and final visual acuities, number and localization (anterior/posterior/panuveitis) of attacks during follow-up, presence of retinal infiltration, retinal hemorrhage and hypopyon uveitis. Candidate factors for damage progression were compared between patients who had a progression in damage score and those who did not.

Results: 98 eyes of 49 patients (M:F 35:14, mean age at baseline $27 \pm 8$ years, mean follow-up duration $20.9 \pm 5.5$ years, mean number of visits $76.5 \pm 35.2$ ) were evaluated. The mean visual acuity was $0.02 \pm 0.08$ at baseline and $0.47 \pm 0.52$ at the final visit. The mean number of attacks was 13.2 \pm 9.4 . Damage grades at baseline were Grade 0 in 79, Grade 1 in 16 and Grade 2 in 3 eyes. Damage grades at final visit were Grade 0 in 15, Grade 1 in 21, Grade 2 in 32, Grade 3 in 12, Grade 4 in 10 and Grade 5 in 8 eyes. There was damage progression in 81/98 eyes at the final visit. Isolated anterior uveitis attacks were not associated with progression of damage $(2.5 \pm 2.9$ vs $2.8 \pm 5.5, p=0.7)$. Parameters that were significantly more frequent among patients with damage progression were number of attacks (14.5 \pm 10.8 vs $23.3 \pm 12.3 ; \mathrm{p}=0.008)$, number of posterior attacks $(0.4 \pm 1.2$ vs $6.5 \pm 4.9, p<0.001)$, number of panuveitis attacks $(0.8$ \pm 1.3 vs $6.6 \pm 5.0, p<0.001)$, number of attacks with severe vitrous opacity preventing examination of the retina ( 0 vs $3.2 \pm 3.8, p<0.001)$, retinal infil tration $(0.2 \pm 0.4$ vs $1.4 \pm 1.9, p<0.001)$ and retinal hemorrhages in the arcuate region $(0.1 \pm 0.2$ vs $0.7 \pm 1.4, p<0.001)$, and the number of hypopyon attacks $(0.2 \pm 1.0$ vs $0.9 \pm 1.3, \mathrm{p}=0.019)$

Conclusion: This study confirmed that the anterior uveitis attacks are not associated with progressive damage in BS, whereas posterior and panu veitis attacks, attacks causing severe vitreous opacity, retinal infiltrates and hemorrhage in the arcuate region and hypopyon attacks are impor tant predictors of damage. Patients showing these features should be treated more aggressively.

\section{REFERENCE}

[1] Ozyazgan, Yilmaz, et al. "Ocular involvement of Behçet's syndrome: a comprehensive review." Clinical reviews in allergy \& immunology 49.3 (2015): 298-306 
Disclosure of Interests: Yilmaz Ozyazgan Speakers bureau: ABBVIE, Didar Ucar: None declared, Mustafa Erdogan: None declared, Yesim Ozguler: None declared, Gulen Hatemi Consultant for: Abbvie, Amgen, BMS, Janssen, MSD, Pfizer, UCB, Speakers bureau: Abbvie, Amgen, BMS, Jansen, MSD, Pfizer, UCB, Sebahattin Yurdakul: None declared, Vedat Hamuryudan Consultant for: Abbvie, Amgen, BMS, Jansen, MSD, Pfizer, UCB, Speakers bureau: Abbvie, Amgen, BMS, Jansen, MSD, Pfizer, UCB, Izzet Fresko: None declared, Melike Melikoglu: None declared, Emire Seyahi: None declared, Serdal Ugurlu: None declared, Hasan Yazici: None declared

DOI: 10.1136/annrheumdis-2019-eular.4317

\section{SAT0224 PRESENTATION, MANAGEMENT AND OUTCOME OF ANCA ASSOCIATED VASCULITIDES IN ITALY: A 20- YEAR FOLLOW-UP STUDY}

Mara Felicetti, Roberto Padoan, Mariagrazia Lorenzin, Augusta Ortolan, Franco Schiavon. Rheumatology, Unit, University of Padova, Italy, Department of Medicine DIMED, Padova, Italy

Background: ANCA associated vasculitis (AAV) are systemic diseases with a wide spectrum of clinical presentation and organ involvement.

Objectives: To analyze presentation, management and 5 years-outcomes of AAV patients diagnosed between 2000 and 2018 in the monocentric cohort of Padova Vasculitis Center.

Methods: We retrospectively collected all AAV patients diagnosed between 2000 and 2018 and followed in the Vasculitis Center of Padova University. We focused on demographic and clinical features at baseline, first line immunosuppressive (IS) treatment, 6 months mortality, 5 years-relapse rate and survival rate and. In the analysis, we kept separate eosinophilic granulomatosis with polyangiitis (EGPA) from granulomatosis with polyangiitis (GPA) and microscopic polyangiitis (MPA).

Results: We identified 171 patients (F/M 93/78) with AAV diagnosed since 2000 (61 between 2000-2010 and 110 between 2011-2018,\% of increased in diagnosis rate $+183 \%)$ : $82(48 \%)$ were GPA, $28(16 \%)$ MPA and $61(36 \%)$ EGPA. The patients were mostly Caucasian $(98 \%)$, with a mean age at diagnosis of $58.4 \pm 16.1$ years, slightly younger if diagnosed in the second decade (2010-2018) than in first decade (2000-2010) (59.5 \pm 16.6 years vs $61.6 \pm 14.7$ years, $p=0.049$ ). ANCA were tested in 163 patients: $23 \%$ ANCA negative, 37\% cANCA/PR3, 39\% pANCA/MPO and $1 \%$ double positive.

GPA/MPA patients were mostly ANCA positive at diagnosis (96/110 patients), in particular we counted 12 (15\%) GPA-ANCA negative patients, 55 (68\%) GPA-PR3, 13 (16\%) GPA-MPO, 1 GPA with double positivity while MPA resulted only ANCA positive, 22 (82\%) MPA-MPO and 5 (19\%) MPA-PR3. In EGPA group, only 28/54 presented with ANCA positivity, all $\mathrm{p}-\mathrm{ANCA} / \mathrm{MPO}$ specificity.

Disease severity at diagnosis was assessed only in GPA/MPA patients: 12/101 limited disease, 34 early systemic, 29 generalized and 26 severe. In particular, GPA/MPA more frequently presented with systemic symptoms (76\%), ENT and lung involvement (respectively $62 \%$ and $66 \%$ ). Renal vasculitis was reported in $65 \%$ of patients with a mean eGFR of $50.2 \pm 39.8 \mathrm{ml} / \mathrm{min}$. Moreover, we registered 17 alveolar haemorrhages, 4 cardiac involvement and 3 gastrointestinal (GI) disease.

EGPA patients, instead, presented more frequently with ENT (85\%) and lung involvement (96\%) (mostly uncontrolled asthma and pulmonary infiltrates). 31 (54\%) EGPA presented nerve involvement (4 with CNS involvement) and $9(16 \%)$ with cardiac involvement. Interestingly, no renal or Gl vasculitis was reported.

The first line IS treatment administered was: cyclophosphamide (CYC) in $66(38 \%)$, rituximab (RTX) in $14(8 \%)$, azathioprine (AZA) in $27(16 \%)$, methotrexate (MTX) in $25(14 \%)$ and mycophenolate (MMF) in only 5 $(3 \%)$.

Mortality rate at 6 months in all cohort resulted of $1.2 \%$ (2 event), while the 5-years survival calculated with Kaplan Meier method was 94.3\% (8 events). All deaths occurred in the GPA/MPA group. A relapse occurred in $36 \%$ of patients, with a significant higher frequency in GPA/MPA than in EGPA (46.3\% vs $17 \%, p=0.017)$.

Conclusion: Our cohort is characterized by significant higher rate of AAV diagnosis in the last decade and this could reflect the increasing incidence and prevalence reported in literature ${ }^{1}$. Interestingly, GPA diagnosis, especially with cANCA/PR3 specificity, was prevalent in our cohort despite some authors reported an higher prevalence of MPA in Mediterrean area $^{1-2}$. Finally, EGPA confirmed a better outcome at last follow up than GPA and MPA, but we noted that no renal and GI involvement was observed in our EGPA patients.

\section{REFERENCE}

[1] Berti A, Dejaco C. Update on the epidemiology, risk factors, and outcomes of systemic vasculitides. Best Pract Res Clin Rheumatol. 2018;32(2):271 294.

[2] Romero-Gómez C, et al. Epidemiological study of primary systemic vasculitides among adults in southern Spain and review of the main epidemiological studies. Clin Exp Rheumatol. 2015;33(2 Suppl 89):S-11-8

Disclosure of Interests: None declared

DOI: 10.1136/annrheumdis-2019-eular.5112

\section{SAT0225 TARGETED SERUM METABOLIC PROFILE IN PATIENTS WITH TAKAYASU ARTERITIS}

Dinesh Kumar ${ }^{1}$, Harikrishnan Gangadharan Nair ${ }^{2}$, Avinash Jain ${ }^{3}$,

Anupama Guleria ${ }^{1}$, Umesh Kumar ${ }^{1}$, Durga Misra ${ }^{3}$, Ramnath Misra ${ }^{3} .{ }^{1} C B M R$,

Lucknow, India; ${ }^{2}$ Sanjay Gandhi Post graduate Institute of Medical Sciences,

Clinical immunology, Lucknow, India; ${ }^{3}$ Sanjay Gandhi Post graduate Institute of

Medical Sciences, Clinical immunolgy, Lucknow, India

Background: Takayasu arteritis (TAK) is a chronic inflammatory arteritis that mainly affects aorta and, its major branches. Often the course is unpredictable and it remains a challenge to assess disease activity despite the availability of acute phase reactants and imaging modalities [1]. Management heavily relies on physician global assessment. Analysis of serum metabolites using nuclear magnetic resonance spectroscopy is a promising exploratory approach towards identifying new biomarkers in TAK which may cast some light on disease pathogenesis and disease activity.

Objectives: Aim of the study was to evaluate the performance of serum amino acids as determinants of disease activity in TAK.

Methods: Patients with TAK fulfilling ACR 1990 criteria were enrolled and disease activity assessed using ITAS2010 and ITAS-A[2]. Samples were analysed using 1D $1 \mathrm{H} 800 \mathrm{MHz}$ Nuclear magnetic resonance spectrometer equipped with a Cryoprobe (at $300 \mathrm{~K}$ ). The spectra were processed and the concentration of amino acids were measured with respect to internal reference metabolite formate assuming its concentration $10 \mu \mathrm{M}$ in commercial software program CHENOMX (www.chenomx.com) and the resulted normalized values were compared using Tukey's multiple comparison test and diagnostic potential was evaluated using receiver operating characteristic (ROC) curve analysis.

Results: 45 active TAK patients with ITAS-A $\geq 4$ and 53 inactive TA patients with median age 27 years [IQR, 22-35 and IQR, 23-37 years respectively] were enrolled. Female to male (F:M) ratio was $3.5: 1$ and 4.9:1 and median duration of illness 5 [IQR, 2-9 years] and 3 [IQR, 1-6 years] years in active and inactive group respectively. Majority had class $\mathrm{V}$ disease. 43 individuals served as health control $(\mathrm{HC})$ with mean age 30 years and F:M ratio of 4.3:1. Serum levels of Phenylalanine (Phe), Tyrosine (Tyr), Histidine (His), Valine (Val) and Alanine (Ala) were found to be decreased in TAK patients suggesting augmented utilization in the immune-metabolic pathways mainly to replenish the energy demand and self-repair mechanism under conditions of inflammation and oxidative stress. An analysis of amino acids ratio revealed significantly higher His/ Tyr, Ala/Tyr and Val/Tyr ratio in $\mathrm{HC}$ when compared to active TAK patients. Ratio were lower in active TAK when compared to inactive TAK patients but only $\mathrm{Val} / \mathrm{Tyr}$ ratio was significant (AUROC, 0.64 and $p$, 0.01). Ratio served as a gradient with lowest value in active disease and gradually increasing and moving towards $\mathrm{HC}$ as disease was getting controlled
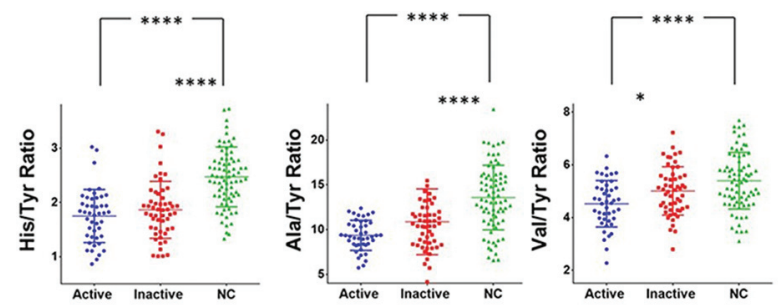

Figure 1: Comparison of various amino acid ratio in active and inactive TAK patient with respect to healthy control. Ratio served as a gradient with lowest in active disease and gradually moving towards $\mathrm{HC}$ as disease was getting controlled.

*significant $\mathrm{p}$ value; Ala, alanine; His, Histidine; NC, Normal healthy control;

Tyr, tyrosine; Val, Valine 